\title{
EFFECT OF TWO RESIN INFILTRATION ON COLOR MASKING OF ARTIFICIAL ENAMEL WHITE SPOT LESION USING DIFFERENT PRETREATMENT METHODS: AN IN VITRO STUDY
}

\author{
Noha Taher Hagag', Ola M. Ibrahim Fahmy², Emad Abd El-Fattah Abo Alazm³
}

DOI: $10.21608 /$ dsu.2020.14906.1006

\section{KEYWORDS}

White spot lesion,

Resin infiltration,

ICON,

Air abrasion,

Spectrophotometer
- E-mail address: email:noohataher@gmail.com

1. B.D.S., Sinai University, 2011.

2. Professor of Operative Dentistry- Head of Restorative Dentistry Department, Faculty of Oral and Dental Medicine, Misr International University

3. Associate Professor of Operative Dentistry (former)- Faculty of Dentistry - Suez Canal University

\section{ABSTRACT}

Aim: This study aimed at investigating the masking effect and depth of penetration of two resin infiltrants (ICON ${ }^{\circledR}$ and unfilled adhesive resin) on artificial white spot lesions after different pretreatment methods (15\% hydrochloric acid, 37\% phosphoric acid and air abrasion through micro etcher) Materials and Methods: Artificial white spot lesions were produced in enamel slabs from 60 freshly extracted permanent human anterior teeth (extracted from diabetic patients). The samples were divided into two main groups: resin infiltrant; ICON ${ }^{\circledR}\left(\mathrm{B}_{1}\right)$ and adhesive resin bond; ONE-STEP $®$ Universal Dental Adhesive $\left(\mathrm{B}_{2}\right)$. Each group was subdivided into three subgroups according to the pretreatment used; $(\mathrm{HCl} 15 \%)$ was applied in $\left(\mathrm{A}_{1}\right),\left(\mathrm{H}_{3} \mathrm{PO}_{4} 37 \%\right)$ was applied in $\left(\mathrm{A}_{2}\right)$ and aluminum oxide particles $(50 / 90 \mu \mathrm{m})$, through micro etcher was applied in $\left(\mathrm{A}_{3}\right)$. The assessment of colour was performed by a spectrophotometer in three distinct stages: baseline, after the production of artificial caries and after infiltration treatment expressed in $\mathrm{L}^{*}, \mathrm{a}^{*}$ and $\mathrm{b}^{*}$ values. To analyze measurement results, the chromatism value, $\Delta \mathrm{E}$ was used to quantify the overall differences of the colors. Results: All the test groups showed no statistically signifiant differences between each other where the highest value was recorded with the adhesive bond after micro-etching $2.250 \pm 0.192$ and the lowest value was recorded with the adhesive bond after $\mathrm{HCl}$ pretreatment $1.710 \pm 0.244$ (Statistical significance is achieved when the P-value $\leq 0.05$ ). Conclusion: Both tested infiltrants reacted similarly and the three tested pretreatment methods were equally effective.

\section{INTRODUCTION}

The presence of detectable, localized areas of enamel demineralization, observed as white spot lesions of different opacity, is a sign that may be the caries process has begun ${ }^{(1)}$. White spot lesions are not only the result of demineralization, as fluorosis, hypo mineralization and hypoplasia can also cause lesions.

Dental professionals are charged with performing a differential diagnosis to determine the etiology of white spot lesions, as well as providing appropriate treatment and esthetic management that will meet patients' expectations ${ }^{(2-4)}$. The increased pore volume inside the lesion body leads to a different refractive index from the sound enamel. Sound enamel has a refractive index (RI) of 1.62 and enamel white 
spot lesions are filled with either a watery medium (RI 1.33) or air (RI 1.0), this difference in refractive indices make the whitish appearance of the lesion. Thus, it impairs mainly the esthetic appearance ${ }^{(5-7)}$.

For esthetic improvement of non-cavitated white spot lesions with remineralized surface, treatment may consist of tooth bleaching, fluoride application, macro abrasion, composite resin bonding, prosthetic restoration or some combination depending on the severity of the lesion and its etiology ${ }^{(\mathbf{8 , 9})}$. It remains unclear which treatment is most effective for white spot lesions. Tooth whitening is the most conservative approach ${ }^{\left({ }^{10}\right)}$. However, tooth whitening treatment alone to camouflage the white spot lesion seemed to be relatively unpredictable. Moreover, if tooth whitening is used in decalcified areas, the microhardness of the enamel surface may be reduced $^{(11-13)}$.

Recently, the resin infiltration technique was introduced as a novel technology that seems to bridge the gap between non-invasive and minimally invasive treatment. The resin infiltration technique prevents further progression of the lesion using a lowviscosity resin with a high penetration coefficient, filling the enamel intercrystallite spaces ${ }^{(14)}$ This technique has been reported to remove the whitish opaque color by perfusing the porous enamel and similarity of refractive indices between infiltrant and enamel thereby changing the color and translucency of the white lesion ${ }^{(15)}$.

Different studies of non-invasive infiltration technology have been conducted, Rocha et al (6) evaluated the performance of different treatments on masking white spot lesions by assessing the color change, they found that resin infiltration was proven to be an effective treatment for masking white spot lesions-Also, Feng and $\mathrm{Chu}{ }^{\left({ }^{(16)}\right.}$ clinically evaluated the effectiveness of ICON infiltration resin on masking of post-orthodontic white spot, and found that resin infiltration was proven to be an ef- fective treatment for masking white spot lesions and that the surface color of infiltrated lesions remained stable after 12 months.

And Paris et al ${ }^{(17)}$ evaluated the ability of one commercial and five experimental infiltrating resins to camouflage enamel white spot lesions immediately after resin infiltration and after a staining period, they concluded that resin infiltration is suitable to mask artificial white spot lesions and is a microinvasive approach to camouflage post orthodontic white spot lesions.

A major challenge for resin infiltration is the need to remove the hyper mineralized surface layer

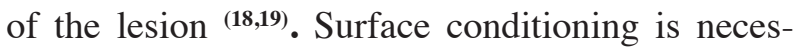
sary because this hyper mineralized surface layer hampers resin infiltration into the lesion. Studies showed that for surface conditioning of the enamel, $15 \%$ hydrochloric acid $(\mathrm{HCl})$ and $37 \%$ phosphoric acid $\left(\mathrm{H}_{3} \mathrm{PO}_{4}\right)$ can be used. Meyer-Lueckel et al ${ }^{(\mathbf{1 8})}$ compared the efficacy of different etching gels in removing the surface layer in various etching times; phosphoric (37\%) and hydrochloric (5 or $15 \%$ ) acid gel for 30-120 sec. They found that an effective reduction in the surface layer of natural enamel caries can be achieved by etching with $15 \%$ hydrochloric acid gel for 90-120 sec.

Paris et al ${ }^{(20)}$ evaluated the effect of phosphoric and hydrochloric acid gels on the surface layer reduction of natural lesions of primary teeth, and found that an effective erosion of the surface layer of natural enamel caries in deciduous teeth could be achieved by etching with $15 \%$ hydrochloric acid gel for $90-120 \mathrm{sec}$.

Air abrasion using micro etcher is one of enamel conditioning methods used frequently by orthodontists in bonding of orthodontic brackets by removing the surface layer and enhancing adhesion (21). Many authors used air abrasion as a surface preteatment such as, Robles-Ruíz et al ${ }^{(22)}$ who found that 
lingual enamel conditioning with aluminum oxide sandblasting before acid etching resulted in greater roughness and produced a conditioning pattern different from that of acid etching alone when evaluated changes in lingual enamel roughness. These investigations mentioned before have been made on the effect of resin infiltrant on masking of artificial white spot lesions. Therefore, the present investigation is designed to investigate the ability of different resin materials to mask the artificial white spot lesions using different pretreatment methods.

\section{MATERIALS AND METHODS}

\section{Materials:}

Two different resin materials and three different pretreatment materials were used in this study (Table 1)

\section{Specimens preparation and grouping}

A total of 60 intact, sound, freshly extracted permanent human anterior teeth (extracted from diabetic patients) were stored in normal saline for this study. The stored teeth were sectioned mesiodistally parallel to the long axis of crown by using a hard-tissue microtome (Isomet. 1000, Buehler Ltd., Lake Bluff, USA) to prepare labial enamel slabs. The enamel slabs (approximately $5 \mathrm{~mm} . x 5 \mathrm{~mm}$. surface area, $0.5 \mathrm{~mm}$ thickness) are cemented on thin acrylic resin bases $(2 \mathrm{~cm} \times 3 \mathrm{~cm})$ by using flowable composite (Meta Biomed, Inc., Chungbuk, Korea). 60 Specimens are then divided into two main groups according to resin used and three subgroups according to the surface pretreatment as mentioned in (Table 2).

Table (1): Specifications, manufacturers and chemical composition of the materials used in the study.

\begin{tabular}{|c|c|c|c|}
\hline Specifications & Material & Manufacturer & Content \\
\hline Resin infiltrant & $\mathrm{ICON}^{\circledR}$ & $\begin{array}{c}\text { (DMG, Hamburg, } \\
\text { Germany) }\end{array}$ & $\begin{array}{l}\text { - Icon-Etch: } 15 \% \text { Hydrochloric acid, pyrogenic si- } \\
\text { licic acid, water, additives. } \\
\text { - Icon-Dry: } 99 \% \text { ethanol } \\
\text { - Icon-Infiltrant: Methacrylate-based resin matrix, } \\
\text { TEGDMA, initiators, additives }\end{array}$ \\
\hline $\begin{array}{l}\text { Unfilled Adhesive } \\
\text { resin bond }\end{array}$ & $\begin{array}{l}\text { ONE-STEP® } \\
\text { Universal Dental } \\
\text { Adhesive. }\end{array}$ & $\begin{array}{l}\text { (Bisco, Schaumburg, } \\
\text { IL, USA) }\end{array}$ & $\begin{array}{ll}\text { - } & \text { BPDM } \\
\text { - } & \text { Bis-GMA } \\
\text { - } & \text { HEMA } \\
\text { - } & \text { acetone } \\
\text { - } & \text { photo-initiator }\end{array}$ \\
\hline $\begin{array}{l}\text { Hydrochloric acid } \\
\text { gel (HCl 15\%) }\end{array}$ & $\begin{array}{l}\text { Available in } \mathrm{ICON}^{\circledR} \\
\text { Kit }\end{array}$ & $\begin{array}{l}\text { (DMG, Hamburg, } \\
\text { Germany) }\end{array}$ & $\begin{array}{l}\text { - } 15 \% \text { Hydrochloric acid } \\
\text { - } \text { pyrogenic silicic acid } \\
\text { - } \text { water } \\
\text { Additives }\end{array}$ \\
\hline $\begin{array}{l}\text { Phosphoric acid } \\
\text { etchant. }\end{array}$ & ETCH-37 TM & $\begin{array}{c}\text { (Bisco, Schaumburg, IL, } \\
\text { USA) }\end{array}$ & $\begin{array}{l}\text { - } 37 \% \text { orthophosphoric acid with Benzalkonium } \\
\text { chloride }\end{array}$ \\
\hline Micro-etcher & Intra-oral sandblaster & $\begin{array}{l}\text { (Danville Engineering } \\
\text { Inc, Danville, } \\
\text { California.) }\end{array}$ & - Aluminum oxide particles $(50 / 90 \mu \mathrm{m})$. \\
\hline Flowable composite & Nexcomp Flow & $\begin{array}{l}\text { (Meta Biomed, Inc., } \\
\text { Chungbuk, Korea) }\end{array}$ & $\begin{array}{l}\text { - TEGDMA(Tetraethyleneglycol Dimethacrylate) } \\
\text { - Silica } \\
\text { - Filler ( } 60 \% \text { by weight, } 0.8 \text { um by size })\end{array}$ \\
\hline
\end{tabular}


Table (2): Variables of the study

\begin{tabular}{|c|c|c|}
\hline Variable & Symbol & Denoting \\
\hline \multirow{2}{*}{$\begin{array}{c}\text { Resin } \\
\text { material }\end{array}$} & $\mathrm{B}_{1}$ & Resin infiltrant \\
\cline { 2 - 3 } & $\mathrm{B}_{2}$ & Unfilled Adhesive resin bond \\
\hline \multirow{4}{*}{$\begin{array}{c}\text { Pretreatment } \\
\text { material }\end{array}$} & $\mathrm{A}_{1}$ & $\mathrm{HCl}(15 \%)$ \\
\cline { 2 - 3 } & $\mathrm{A}_{2}$ & $\mathrm{H}_{3} \mathrm{PO}_{4}(37 \%)$ \\
\cline { 2 - 3 } & $\mathrm{A}_{3}$ & $\begin{array}{c}\text { Aluminum-oxide particles } \\
(50 / 90 \mu \mathrm{m}) \text {, used through mi- } \\
\text { cro etcher. }\end{array}$ \\
\hline
\end{tabular}

\section{Preparation of White Spot- Like Lesions}

Enamel surface of each specimen was partly covered with acid-resistant nail varnish, leaving an experimental window of sound enamel of about ( $3 \mathrm{~mm} \times 3 \mathrm{~mm}$ ). Specimens were then demineralized using citric acid solution at $\mathrm{pH} 4.4$ supplied in a dark bottle kept at room temperature $\left(25^{\circ} \mathrm{C}\right)$, and were kept for 24 hours. $\mathrm{PH}$ was monitored during storage. The specimens were checked for white spot lesions (WSLs) visually by appearance of the chalky white color.

\section{Experimental Design}

According to the assigned groups, the demineralized enamel specimens were pretreated prior to ICON and unfilled adhesive resin bond infiltration. according to the manufacturer's instructions.

- $15 \%$ hydrochloric acid gel (ICON-Etch; DMG, Hamburg, Germany) was applied over the artificial WSL and left for 2 minutes then rinsed for $30 \mathrm{sec}$. with water jet followed by drying with oil-free compressed air for $20 \mathrm{sec}$

- $\quad 37 \%$ phosphoric acid gel (Bisco, Schaumburg, IL, USA) was applied over WSL surface directly from the acid syringe and left for $30 \mathrm{sec}$, conditioned surface was rinsed with water jet for 15 sec. and oil-free compressed air dried for $20 \mathrm{sec}$.

- Micro-etcher (Danville Engineering Inc, Danville, California.), aluminum oxide powder was used with $50-\mu \mathrm{m}$. particles size at 130 psi for $20 \mathrm{sec}$. at a distance of $6 \mathrm{~mm}$. The specimens were then rinsed with water jet spray for 30 sec. and dried with compressed oil-free air for $20 \mathrm{sec}$. The pretreated subgroups were divided into two main groups according resin material used (Table 2). In the first group, resin infiltrant; ICON ${ }^{\circledR}$ (DMG, Hamburg, Germany) was used according to the manufacturer's instructions through the:

- Application of ethanol-drying agent, ICON-Dry (99\% ethanol) supplied in a syringe in the ICON kit, this drying step involves $30 \mathrm{sec}$. of application of the ICON-Dry followed by compressed oil-free air drying.

- ICON-Infiltrant, a resin with a high penetration coefficient, was then applied with the supplied applicator in a series of two applications, first for 3 minutes and then for an additional 1 minute and cured after each application for $40 \mathrm{sec}$. (QHL 75TM, Dentsply Corporate, USA).

In the second group, unfilled adhesive resin bond; ONE-STEP ${ }^{\circledR}$ Universal Dental Adhesive (Bisco, Schaumburg, IL, USA) are used by following steps:

- Adhesive system was applied with micro brush (Multi BrushTM, Denbur Inc, IL, USA) for 1-minute followed by compressed oil-free air drying for $3 \mathrm{sec}$.

- A second application of adhesive system was done with the micro brush for 1 minute and dried with compressed oil free air drying for another $3 \mathrm{sec}$. then light cured for $40 \mathrm{sec}$. (QHL 75TM, Dentsply Corporate, USA).

\section{Specimens color measurement:}

Color measurements for the 60 samples were performed 3 times; before the production of artificial white spot lesion (Baseline color), each window of the sample was determined using spectrophotometer (Beckman Coulter Inc., USA). After production of artificial WSLs were completed, the second color 
measurement was performed (demineralized color). After infiltration treatment, the third color measurement was conducted after the infiltration resin was coated (after infiltration color). Spectrophotometer was calibrated according to the manufacturer's instructions. All spectrophotometric measurements were measured in a full spectrum, color corrected environment with color temperature of $5,500 \mathrm{~K}$ with no outside ambient light and neutral-colored surroundings and performed by one operator to reduce error. When the site of measurement on the specimen was vertically close to the window under the test, the built-in light source radiated light. A few seconds later, the results of measurement were displayed on the screen. The parameters included values of $\mathrm{L}^{*}, \mathrm{a}^{*}$, and $\mathrm{b}^{*}$. The data pattern automatically used the average of the 3 measurement values. To analyze measurement results, the chromatism value, $\Delta \mathrm{E}$ was used to quantify the overall differences of the colors.

\section{Equation of $\Delta \mathrm{E}$ calculation:}

$$
\Delta E^{*}{ }_{L a b}=\left[\left(\Delta L^{2}\right)+\left(\Delta a^{2}\right)+\left(\Delta b^{2}\right)\right]^{1 / 2}
$$

\section{Statistical Analysis}

Statistical analyses were carried out using SPSS version 23.0. Data analysis included descriptive statistics, one and two-way analysis of variance (ANOVA) at $p$-value $<0.05$ to assess differences between pre-treatments $(\mathrm{HCl}$, phosphoric, and microetching) and infiltrants (Icon/bond). One and twoway analysis of variance were followed by Duncan's multiple range tests (DMRTs). Differences between two different resin infiltrants were assessed using independents and paired samples t-test followed by two-tailed

\section{RESULTS}

Colour measurements results represent the effect of different resin infiltrants and surface pretreatments on the mean $\Delta \mathrm{E}$. Duncan Multiple range comparison was used to assess differences between different treatments (Mineralized; Last), pre-treatments (Hydrochloric acid, phosphoric acid, and micro-etching) and Icon/bond. Demineralized enamel showed the highest $\Delta \mathrm{E} 4.57 \pm 0.408$ which is statistically significant compared to all tested groups. While all the test groups showed no statistically differences between each other where the significantly highest value was recorded with the adhesive bond after micro-etching $2.250 \pm 0.192$ and the lowest value was recorded with the adhesive bond after $\mathrm{HCl}$ pre-treatment $1.710 \pm 0.244$ (Statistical significance is achieved when the P-value $\leq 0.05$ ). (Table 3) (Figure1,2).

Table (3) Descriptive statistics of $\Delta \mathrm{E}$, expressed as mean \pm standard deviation (SD) and followed by Univariate ANOVA at $p$-value $<0.05$.

\begin{tabular}{|c|c|c|c|}
\hline \multicolumn{2}{|l|}{ Treatment } & \multicolumn{2}{|c|}{$\Delta \mathrm{E}($ mean $\pm \mathrm{SD})$} \\
\hline \multicolumn{2}{|l|}{ (1) Demineralization } & \multicolumn{2}{|c|}{$4.57 \pm 0.408 b$} \\
\hline Treatment/ & Pre-treatment & $\Delta \mathrm{E}$ Icon \pm SD & $\Delta \mathrm{E}$ Bond \pm SD \\
\hline \multirow[t]{3}{*}{ (2) LAST treatment } & Hydrochloric & $2.040 \pm 0.198 \mathbf{a}$ & $1.710 \pm 0.244 \mathbf{a}$ \\
\hline & Phosphoric & $1.890 \pm 0.286 \mathbf{a}$ & $1.950 \pm 0.363 \mathbf{a}$ \\
\hline & Micro-etching & $1.990 \pm 0.406 \mathbf{a}$ & $2.250 \pm 0.192 \mathbf{a}$ \\
\hline \multicolumn{4}{|c|}{ Two-Way Analysis of variance } \\
\hline $\mathrm{F}$ (corrected) & $102.45^{* * *}$ & $\mathrm{~F}$ (pre-treatment) & 1.27 n.s. \\
\hline F (Icon/ bond) & 0.001 n.s. & $\mathrm{F}$ (Icon/bond X pre-treatment) & 1.69 n.s. \\
\hline
\end{tabular}

$*$ Significant at $p<0.05 ; * *$ highly significant at $p<0.01 ; * * *$ very high significant at $p<0.001$. Means with similar letters are not significantly different according to Duncan's multiple range comparisons. 


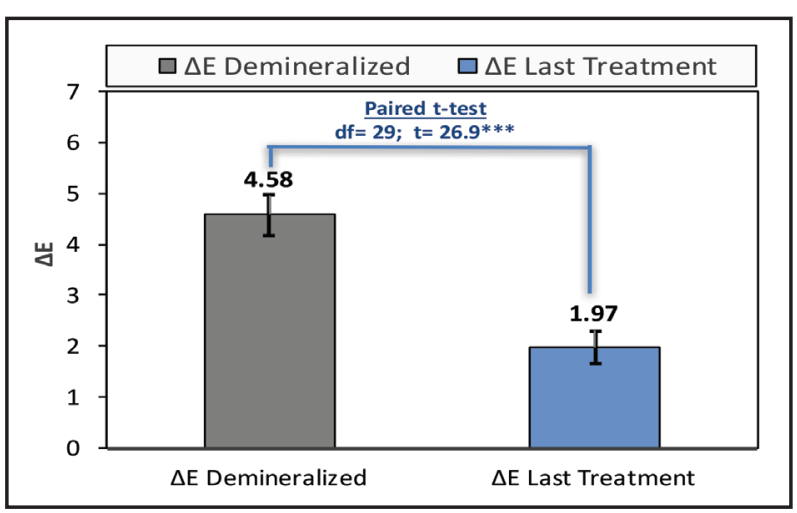

Fig. (1) Histogram showing effect of Last treatment and demineralization on $\Delta \mathrm{E}$, expressed as mean and bars represent the standard deviation (SD)

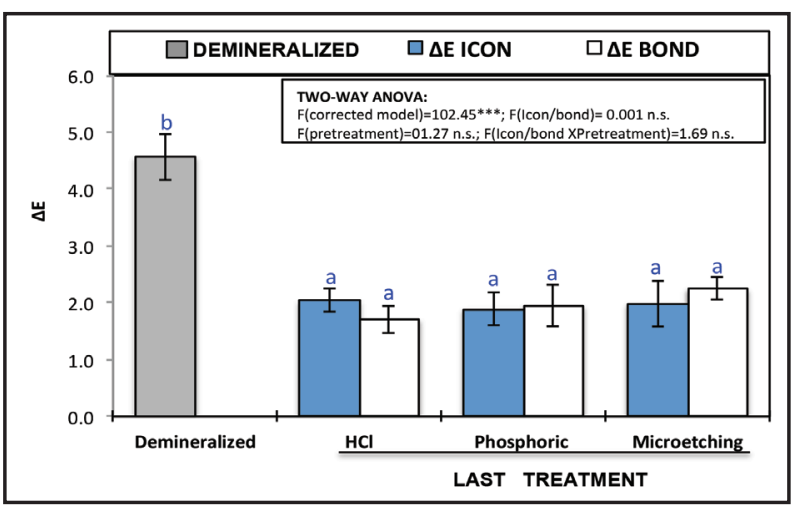

Fig. (2) Histogram showing the effect of different surface treatments and resin infiltrants on mean $\Delta \mathrm{E}$.

\section{DISCUSSION}

ICON was introduced as a treatment modality for treating early WSLs. It is a low-viscosity lightcuring resin that have been optimized for rapid penetration into the porous enamel and proved to be effective for improving the esthetic appearance ${ }^{(\mathbf{1 7})}$.

However, in previous studies different resin infiltrants proved to have similar role in masking effect ${ }^{(23,24,25)}$. In the current study, ONE-STEP $®$ Universal Dental Adhesive (Bisco, Schaumburg, IL, USA) was selected because it was unfilled resin in contrast to the previously tested.
Regarding the surface treatments, $\mathrm{HCl}$ was selected as it is the pretreatment recommended by the manufacturer, $\mathrm{H}_{3} \mathrm{PO}_{4}$ was recommended for use prior to the adhesive resin ${ }^{(25)}$ and air-abrasion was included in this study because it can successfully remove the a prismatic enamel, exposing the underlying prismatic structure that might enhance the resin infiltrants penetration ${ }^{(26)}$.

Several methods can be used to measure the tooth color such as visual assessment with ranges of color photographs and computer analysis of the images or specific devices for color analysis, e.g., colorimeters and spectrophotometers ${ }^{(27)}$. Spectrophotometers enable objective color assessment, provide precise quantitative data, more accurate and more reproducible, therefore it was the selected method used in this study ${ }^{(28,29)}$.

It was reported that human observers can be expected to detect color differences of one $(\Delta E)$ unit under standardized laboratory conditions. In the oral cavity, where the light source cannot be standardized, $\Delta \mathrm{E} \leq 3.7$ units was considered to be a match for compared teeth ${ }^{(30)}$. According to Johnston and Kao ${ }^{(31)}$ a color change is considered clinically visible when $\Delta \mathrm{E}$ is higher than 3.7 units ${ }^{(32)}$. Demineralization of the samples to create artificial white spot lesions led to $\Delta \mathrm{E}$ equivalent to 3.9 4.9 which is within the clinically perceptible range.

Regarding the effect of resin material on the color masking, $\triangle \mathrm{E}$ between baseline color and infiltrated lesions color ranged between 1.3 and 2.3, so both resin materials used in this study could clinically mask the color of white spot lesion. However, comparing both tested materials showed no statistically significant difference in masking whitish color of lesion.

This finding agrees with Paris et al ${ }^{(17)}$ who evaluated the ability of one commercial and five experimental infiltrating resins (infiltrants) to camouflage 
enamel white spot lesions immediately after resin infiltration and after a staining period. According to $\Delta \mathrm{E}$ and refractive index, all tested infiltrants showed significantly acceptable color match with sound enamel.

Also, this result was in agreement with de Lacerda et al ${ }^{(23)}$ who evaluated the color masking effect of infiltration treatment of artificial white spot lesions (AWSLs) using ICON in comparison to different adhesive systems using spectrophotometer, in relation to $\Delta \mathrm{E}$ means, all agents applied were significantly effective in color masking of artificial white spot lesions. The refractive indices of the materials that effectively masked white spots were very similar to the ICON product. This similarity could help explain their performances.

On the other hand, this finding was in disagreement with Abdellatif and El-Sebaai ${ }^{(33)}$ who evaluated the effect of resin infiltrant on white spot lesions compared to adhesive resin. The ICON group showed a highly significant color improvement compared to the other groups. The other test groups also showed significant color improvement but not as the ICON group. They explained their result by the fact that the physical proprieties of infiltrant like its contact angle with enamel, surface tension and its viscosity affect its penetration which improve color masking effectiveness and microhardness. ICON group also showed significantly higher surface microhardness.

Regarding the effect of surface treatment before infiltration on color masking, the current study showed there was no statistically significant difference between three methods used, hydrochloric acid $(\mathrm{HCl})$, phosphoric acid $\left(\mathrm{H}_{3} \mathrm{PO}_{4}\right)$ and air-abrasion by using micro etcher.

This is with in agreement with previously mentioned study made by Paris et al ${ }^{(17)}$ used $\mathrm{H}_{3} \mathrm{PO}_{4}$ and $\mathrm{HCl}$ as pretreatment methods before testing the abil- ity of infiltarnts to mask WSLs color. They found there was no significant difference between $\mathrm{H}_{3} \mathrm{PO}_{4}$ and $\mathrm{HCl}$ regarding color masking.

The current in vitro study did not examine the effect of different oral environmental factors on the efficiency and long-term durability of the tested treatments which might modify the perceived results. Therefore, further in vivo studies with longer periods of follow up are necessary to confirm the efficiency of the tested infiltarnts, examine their color stability and encourage the clinicians to use it in their dental practice.

\section{CONCLUSIONS}

Under the conditions of the present study the following conclusions could be derived:

\section{Concerning color masking:}

- Both tested infiltrants reacted similarly.

- The three tested pretreatment methods were equally effective.

\section{REFERENCES}

1. Cochrane NJ, Cai F, Huq NL, Burrow MF, Reynolds EC. New approaches to enhanced remineralization of tooth enamel. J Dent. Res 2010; 89:1187-1197,

2. Seow WK. Developmental defects of enamel and dentin: challenges for basic science research and clinical management. Aust. Dent. J 2014; 59:143-154.

3. Kidd EA, Fejerskov O. What constitutes dental caries? Histopathology of carious enamel and dentin related to the action of cariogenic biofilms. J Dent. Res.; 83:35-38, 2004

4. Ellwood RP, O'Mullane D. Enamel opacities and dental esthetics. J Public Health Den 1995; 55:171-176.

5. Ardu S, Castioni NV, Benbachir N, Krejci I. Minimally invasive treatment of white spot enamel lesions. Quintessence Int 2007; 38:633-636.

6. Rocha Gomes Torres C, Borges AB, Torres LM, Gomes IS. Effect of caries infiltration technique and fluoride therapy on the color masking of white spot lesions. J Dent 2011; 39:202-207. 
7. Kim S, Kim EY, Jeong TS, Kim JW. The evaluation of resin infiltration for masking labial enamel white spot lesions. Int. J Paediatr. Dent 2011; 21:241-248.

8. Bussadori SK, do Rego MA, da Silva PE, Pinto MM, Pinto AC. Esthetic alternative for fluorosis blemishes with the usage of a dual bleaching system based on hydrogen peroxide at 35\%. J Clin Pediatr Dent 2004; 28:143-146

9. Goldstein RE. Esthetics in dentistry. 2nded. Hamilton: B.C. Decker; 2001 .

10. Michael Knosel, Rengin A, Klaus B, Thomas A. External bleaching effect on the color and luminosity of inactive white-spot lesions after fixed orthodontic appliances. Angle Orthod 2007; 77:647-652.

11. Basting RT, Rodrigues Júnior AL, Serra MC. The effect of $10 \%$ carbamide peroxide bleaching material on microhardness of sound and demineralized enamel and dentin in situ. Oper. Dent 2001; 26:531-539.

12. Malterud MI. Minimally invasive restorative dentistry: a biomimetic approach. Pract Proced Aesthet Dent 2006; 18:409-414

13. Stahl J, Zandona AF. Rationale and protocol for the treatment of non-cavitated smooth surface carious lesions. Gen. Dent 2007; 55:105-111.

14. 14. Paris S, Meyer-Lueckel H, Cölfen H, Kielbassa AM. Resin infiltration of artificial enamel caries lesions with experimental light curing resins. Dent Mater J 2007; 26:582-588.

15. Weisrock G, Terrer E, Couderc G, Koubi S, Levallois B, Manton D, Tassery H. Naturally aesthetic restorations and minimally invasive dentistry. J Minim. Interv. Dent 2011;4:23-30.

16. Feng C., CHU X. Efficacy of one-year treatment of icon infiltration resin on post-orthodontic white spots. PUHS J 2013; 45: 40-44.

17. Paris S, Schwendicke F, Keltsch J, Dörfer C, MeyerLueckel H. Masking of white spot lesions by resin infiltration in vitro. J Dent 2013;41: 1010-1016

18. Meyer-Lueckel H, Paris S, Kielbassa AM. Surface layer erosion of natural caries lesions with phosphoric and hydrochloric acid gels in preparation for resin infiltration. Caries Res 2007;41(3):223-230.

19. Paris S, Meyer-Lueckel H, Kielbassa AM. Resin infiltration of natural caries lesions. J Dent. Res 2007;86(7):662-666

20. Paris S, Keltsch J, Dörfer CE, Meyer-Lückel H. Visual assimilation of artificial enamel caries lesions by infiltration in vitro. Caries Res 2010; 44: 171-178.
21. Turkoz C, Ulusoy C. Evaluation of different enamel conditioning techniques for orthodontic bonding. Korean $\mathrm{J}$ Orthod 2012; 44: 32-38.

22. Robles-Ruíz JJ, Arana-Chavez VE, Ciamponi AL, Abrão J, Kanashiro LK. Effects of sandblasting before orthophosphoric acid etching on lingual enamel: In-vitro roughness assessment. Am J Orthod Dentofacial Orthop 2015;147:76-81.

23. de Lacerda AJ, Avila DM, Borges AB, Pucci CR, Rocha Gomes Torres C. Adhesive systems as an alternative material for color masking of white spot lesions: Do They Work? J Adhes Dent 2016;18:43-50.

24. Zhao YH, Ci XK, Zeng LW. Masking white spots of enamel in caries lesions with a non-invasive infiltration technique in vitro. Genet. Mol. Res 2014;13:6912-6919.

25. Askar H, Lausch J, Dörfer CE, Meyer-Lueckel H, Paris S. Penetration of micro-filled infiltrant resins into artificial caries lesions. J Dent 2015;43:832-838.

26. Patcas R, Zinelis S, Eliades G, Eliades T. Surface and interfacial analysis of sandblasted and acid-etched enamel for bonding orthodontic adhesives. Am J Orthod Dentofacial Orthop 2015;147:64-75.

27. Gerard Kugel G, Arsenaul P, Papas A. Treatment modalities for caries management, including a new resin infiltration system. Compendium J 2009; 30:1-10.

28. Corekci B, Irgin C, Malkoc S, Ozturk B. Effects of staining solutions on the discoloration of orthodontic adhesives: an in-vitro study. Am. J Orthod. Dentofacial Orthop 2010; 138:741-746.

29. Horn DJ, Bulan-Brady J, Hicks ML. Sphere spectrophotometer versus human evaluation of tooth shade. J Endod.; 24:786-790, 1998

30. Van Meerbeek B., Vargas M., Inoue S., Yoshida Y., Perdigão J., Lambrechts P., Microscopy Investigations. Techniques, Results, Limitations. Am J Dent 2000; 13:3-18.

31. Johnston WM, Kao EC. Assessment of appearance match by visual observation and clinical colorimetry. J Dent Res 1989; 68: 819-822.

32. Paul S, Peter A, Pietrobon N, Hammerle CH. Visual and spectrophotometric shade analysis of human teeth. J Dent. Res 2002; 81:578-582.

33. Abdellatif AB, El-Sebaai HS. Effects of resin application on white spot lesions (laboratory study). J Clin. Pediatr. Dent 2016; 46: 120-126. 